\title{
Synthesis of Faujasite from Egyptian Clays: Characterizations and Removal of Heavy Metals
}

\author{
Mohamed A. Moneim, Ezzat A. Ahmed \\ Geology Department, Faculty of Science, Assiut University, Assiut, Egypt \\ Email: m moneim58@yahoo.com
}

Received 22 March 2015; accepted 12 April 2015; published 15 April 2015

Copyright (C) 2015 by authors and Scientific Research Publishing Inc.

This work is licensed under the Creative Commons Attribution International License (CC BY).

http://creativecommons.org/licenses/by/4.0/

(c) (i) Open Access

\section{Abstract}

Three clay samples with different mineral compositions (kaolinite, smectite-kaoline, and smectite-rich) were used for zeolite synthesis using the method of hydrothermal reactions after fusion with $\mathrm{NaOH}$. The conditions of hydrothermal crystallization (zeolitization) were found to be at temperature of $100^{\circ} \mathrm{C}$, and time span between $72 \mathrm{~h}$ and $96 \mathrm{~h}$ for kaoline and smectite-rich samples, while $48 \mathrm{~h}$ for the smectite-kaolinite sample. The results indicate that zeolites began to crystallize from clay samples after $48 \mathrm{~h}$, and crystallization increased with increasing time. The synthetic materials have been characterized by X-ray diffraction (XRD), scanning electron microscope (SEM), fourier transform infrared spectroscopy (FT-IR) and thermogravimetric (DTA/TGA) analysis. The results indicate that low silica NaX-faujasite type with well-developed octahedral and cubic crystals was synthesized from the three samples. No big difference in the characterization between the three synthetic materials was detected, but smectite-kaolinite sample as raw material was relatively better in crystallization of synthetic zeolite. Applications of the synthetic materials in the removal of heavy metals proved that the synthetic faujasite has strong effect for removing of $\mathrm{Cr}^{3+}$, $\mathrm{Co}^{2+}, \mathrm{Ni}^{2+}$ and $\mathrm{Mn}^{2+}$ from aqueous solution.

\section{Keywords}

Faujasite, Kaoline, Smectite, Hydrothermal Reactions, Zeolite, Clay

\section{Introduction}

Zeolites are crystalline microporous aluminosilicate consisting of tetrahedral units producing open framework structure, which generates a system of pores and cavities having molecular dimensions [1]. And due to their 
thigh, exchange capacity and sieve properties have been used by many workers in water purifications from heavy metals, ammonia and water softening. From the early 1940's on wards, systematic synthesis studies on zeolites were started [2]. Due to the unique properties of zeolites, extensive attempts for zeolite synthesis were begun [3]. Nowadays, the increasing interest in zeolite synthesis from low-cost materials has promoted the development of various studies on their conversion into zeolitic materials, giving rise to an extensive literature [4]. At present, there are 191 unique zeolite frameworks identified [5], and over 40 naturally occurring zeolite frameworks are known. Many authors used natural clays as start materials for zeolite synthesis. Clay minerals such as kaolinite, illite, montmorillionite, and interstratified illite-smectite have been used as the sources of $\mathrm{Al}$ and Si for the synthesis of several types of zeolites [1] [6]-[15]. Synthetic zeolites with faujasite structure have been prepared by designated zeolite X [16], and by zeolite Y [17]. The differences existing between these substances are compositional and depending on the silica to alumina ratio of their framework. In $\mathrm{X}$ zeolites, the ratio is between 2 - 3, while in Y zeolites it is 3 or higher [18]. Zeolites have been studied in terms of the relations among structure, properties and synthesis. The zeolites of class faujasite (NaX, NaY, LTA) are used mainly as ion exchangers, adsorbents or catalysts in chemical, oil refining, gas industries and water softening and purification (Georgiev et al., 2013). Kaolinite is the basic raw material used to obtain zeolite with faujasitic structure and with low content of $\mathrm{SiO}_{2}$ such as $\mathrm{NaX}, \mathrm{NaY}$ and LTA [6] [19]. The objective of this work is to prove which type of natural clay of the studied samples is better in zeolite synthesis using the method of [6], as well as evaluation of the products as waste water purification for heavy metals.

\section{Materials and Methods}

Natural clays were used by many workers as starting materials in zeolite synthesis. In the present study to achieve this purpose, samples of clays with different composition were collected from different locations of Egypt (Figure 1). The samples are Kaolinite from Malha Formtion at El Dehisa mine southwestern Sinai. The Malha Formationm is built up of four distinct white kaolinite horizons interbedded with sandstones (Figure 1). Smectite-rich clay of Abu Tartur, which belong to black shale interbedded with glauconites and phosphorites (Duwi Formation). The third clay sample used here was picked out from the brick-red mudstones and grey siltstones with kaolinite-smectite composition (Madmoud Formation, Said 1981) exposed at Wadi El-Assuitti and Gahdam areas-Asyut, Egypt.

\subsection{Zeolite Synthesis}

Rios et al. (2009) used two different processes for zeolite synthesis from natural clays: 1) conventional hydrothermal alkaline activation and 2) alkaline fusion prior to hydrothermal reaction. The clay samples were prepared zeolite synthesis were carried out based on the second method of Rios et al. (2009) through the following steps:

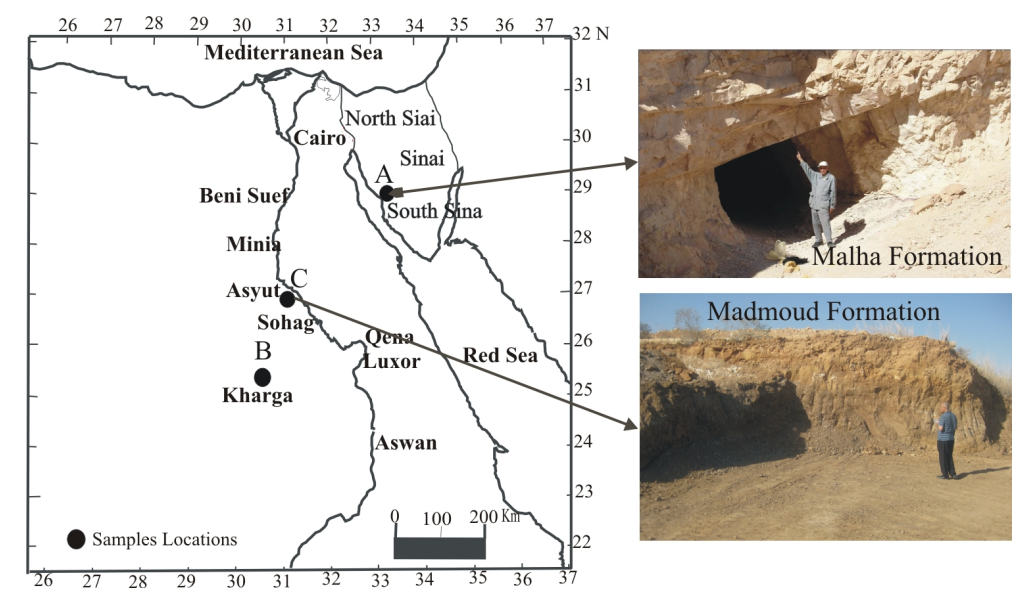

(a)

(b)

Figure 1. Location map for the raw material clay samples. A. Koalinite; B. Smectite-rich; C. Kolinite-Smectite clays. 
1) Calcined raw materials were mixed with $\mathrm{NaOH}$ pellets for $30 \mathrm{~min}$.

2) The resultant mixture was fused at $600^{\circ} \mathrm{C}$ for 1 hour.

3) The alkaline fused products were ground in a mortar and then dissolved in distilled water with stirring for 30 min.

4) The reaction gel was aged $24 \mathrm{~h}$ to form amorphous precursors.

5) Crystallization was carried out by hydrothermal reactions under static conditions in PTFE vessels of $100 \mathrm{ml}$ at $100^{\circ} \mathrm{C}$ for different reaction times $(48,72$ and $96 \mathrm{~h})$.

6) The solid is separated by filtration, washed thoroughly several times with distilled water until the filtrate $\mathrm{pH}$ was reduced to less than 11 .

7) The precipitated solid was dried at $100^{\circ} \mathrm{C}$ overnight.

8) The dried samples were weighted and kept in plastic bags for characterization.

\subsection{Characterization}

$\mathrm{X}$-ray diffraction patterns of raw clay samples and synthesis products were recorded using Ni-filtered $\mathrm{Cu}-\mathrm{Ko} 3$ radiation X-ray diffractometer between $5^{\circ}$ and $50^{\circ} 2 \theta$ with speed rate $06^{\circ} / \mathrm{min}$ at Assiut University (Figure 2). Moreover, the clay fraction $(<2 \mu \mathrm{m})$ of the brick-red mudstones of the Madmoud Formation was separated and treated with ethylene glycol for two hours and heated to $550^{\circ} \mathrm{C}$, then investigated by X-ray diffraction at $2 \theta$ between 4 and 40. The structure of the synthetic products was studied by methods of XRD, SEM, FTIR-spectroscopy, and thermal gravimetric analysis (DTA/TGA).

\subsubsection{X-Ray Diffraction}

As shown in the XRD patterns (Figure 2), kaoline is the predominant mineral phase in the raw material clay sample from Malha Formation (Southwestern Sinai), which can be identified by its distinctive reflections at $12.25^{\circ}$ and $24.84^{\circ}$ (Figure 2(a)) near to that reported by Zhao et al. (2004). Smectite is the predominant mineral phase in the raw material clay sample from Abu Tartur Formation, and is identified by a series a basal at $15.77 \AA$ and $5.6^{\circ} 2 \theta$ (Figure 2(b)). The clay sample from the Nile Valley (Madmoud formation-Assiut) composed mainly of kaolinite-smectite and is identified by its distinctive reflections at $4^{\circ}, 6.29^{\circ}, 11.93^{\circ}$ and $24.58^{\circ}$ $2 \theta$ (Figure 2(c)). In all raw clay samples, quartz was identified at $4.26 \AA$ and $3.35 \AA$. The later peak of quartz was more intense than the other peaks as shown in Figure 2. An almost complete transformation of the starting clay rich raw materials into faujasite-type zeolite of high purity occurred. However, relictic quartz of the starting materials still remains in the synthetized products. Complete disappearance of the characteristic peaks of clay minerals, accompanied by gradual decrease in peak intensity of quartz, and the appearance of zeolites was recorded after $48 \mathrm{~h}$ and showing an increase in the intensity of characteristic peaks between 48 and $96 \mathrm{~h}$ (Figure 2). The broad peaks at around $6^{\circ}, 10^{\circ}, 16^{\circ}, 23.5^{\circ}, 27^{\circ}, 31^{\circ}, 32^{\circ}$, and $37^{\circ} 2 \theta$ are consistent with NaX-type.

\subsubsection{Scanning Electron Microscope (SEM)}

To characterize the morphology of the synthetic zeolite SEM images were investigated. Figure 3 demonstrated the occurrence of well crystallized cubic and octahedral morphology of the synthetic materials. Such morphology is characteristic to faujasite-type zeolite [6] [20]-[23].

\subsubsection{Fourier Transform Infrared (FT-IR) Spectroscopy}

The characterization of zeolites with transmission Fourier transform infrared spectroscopy (FT-IR) is described (Figure 4). FT-IR spectroscopy is used to probe the structure of zeolites and monitor reactions in zeolite pores. Specifically, structural information can be obtained from the vibrational frequencies of the zeolite lattice observed in the range between 200 and $1500 \mathrm{~cm}^{-1}$ [24] [25]. In general, each zeolite has characteristic infrared pattern however, some common features are observed which, include the asymmetric $\left(950-1250 \mathrm{~cm}^{-1}\right)$ and symmetric stretch $\left(660-770 \mathrm{~cm}^{-1}\right)$, double ring vibration $\left(500-650 \mathrm{~cm}^{-1}\right)$, T-O bending modes $(420-500$ $\mathrm{cm}^{-1}$ ), and possibly opening modes $\left(400-420 \mathrm{~cm}^{-1}\right)$.

The IR-spectral data of the synthesized zeolites and NaX, Y, LTA zeolites are presented in Table 1. The double ring opening vibration $564 \mathrm{~cm}^{-1}$ in the FT-IR spectrum of the synthesized zeolites is near to $566 \mathrm{~cm}^{-1}$, which is characteristics to faujasite [22]. The bands at 444, 463, 467, and 672, 669 are assigned to the internal linkage vibrations of $\mathrm{TO}_{4}(\mathrm{~T}=\mathrm{Si}$ or $\mathrm{Al})$ tetrahedral and to symmetrical stretching respectively. These absorption bands characterizing $\mathrm{T}-\mathrm{O}$ bending vibrations may shifted to lower frequencies due to decreasing $\mathrm{Si} / \mathrm{Al}$ ratio in 
M. A. Moneim, E. A. Ahmed

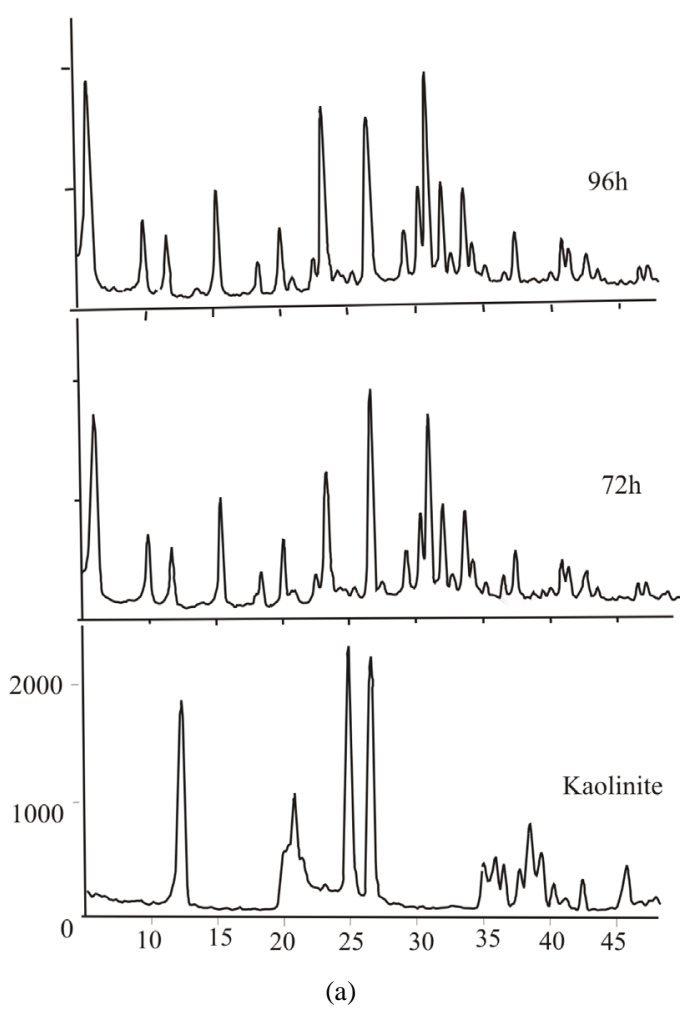

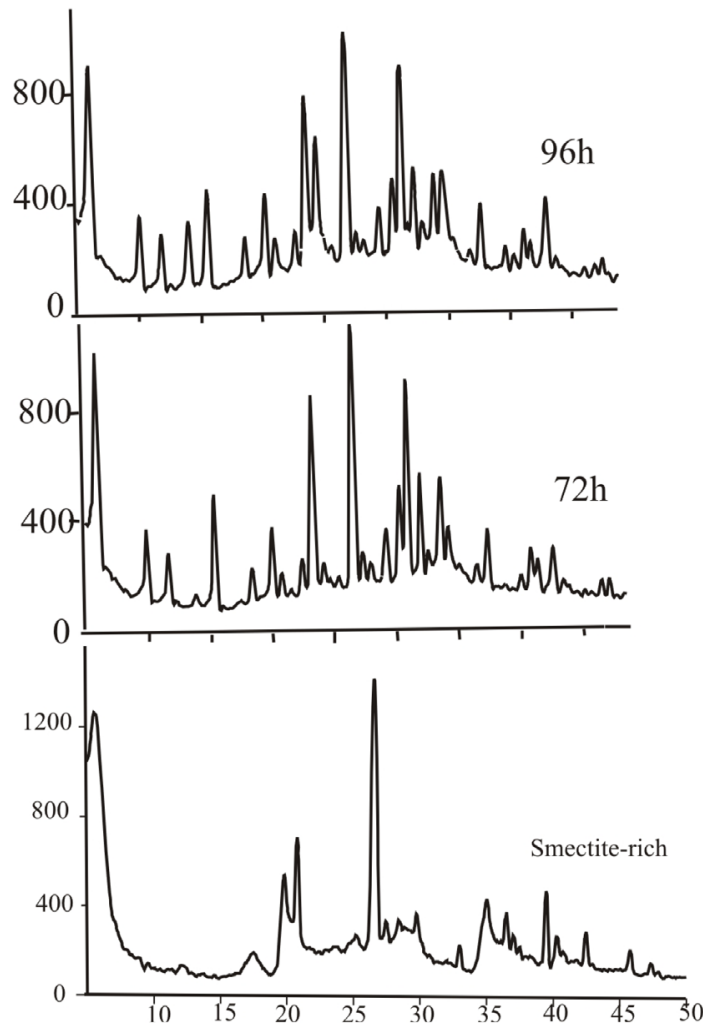

(b)

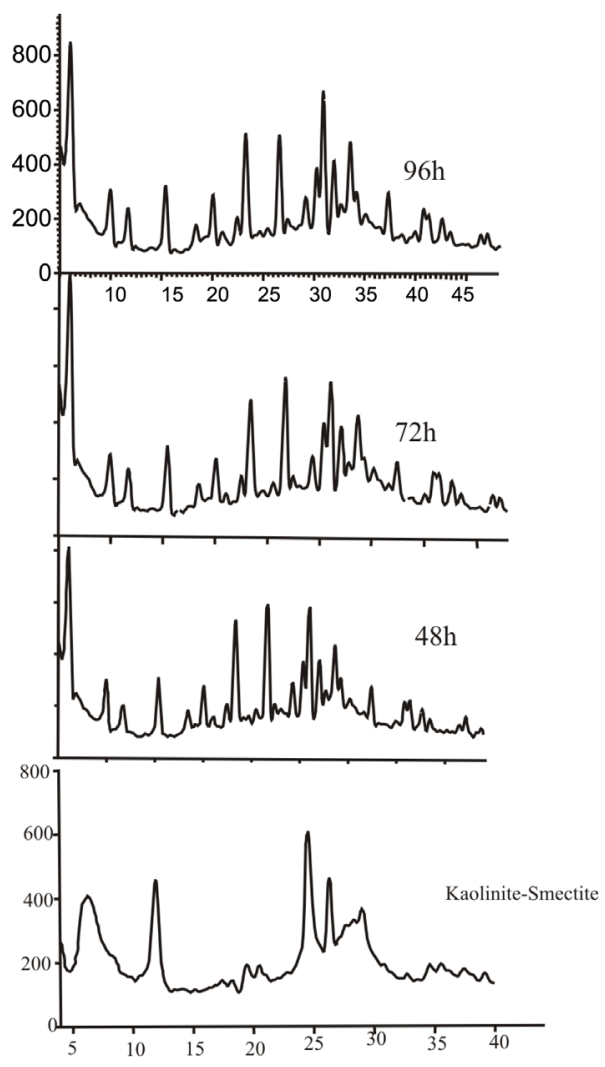

(c)

Figure 2. XRD patterns of raw materials and synthetic zeolite. (a) From kaolinite; (b) From smectite-rich clay; (c) From kaolinite-smectite clay.

71 

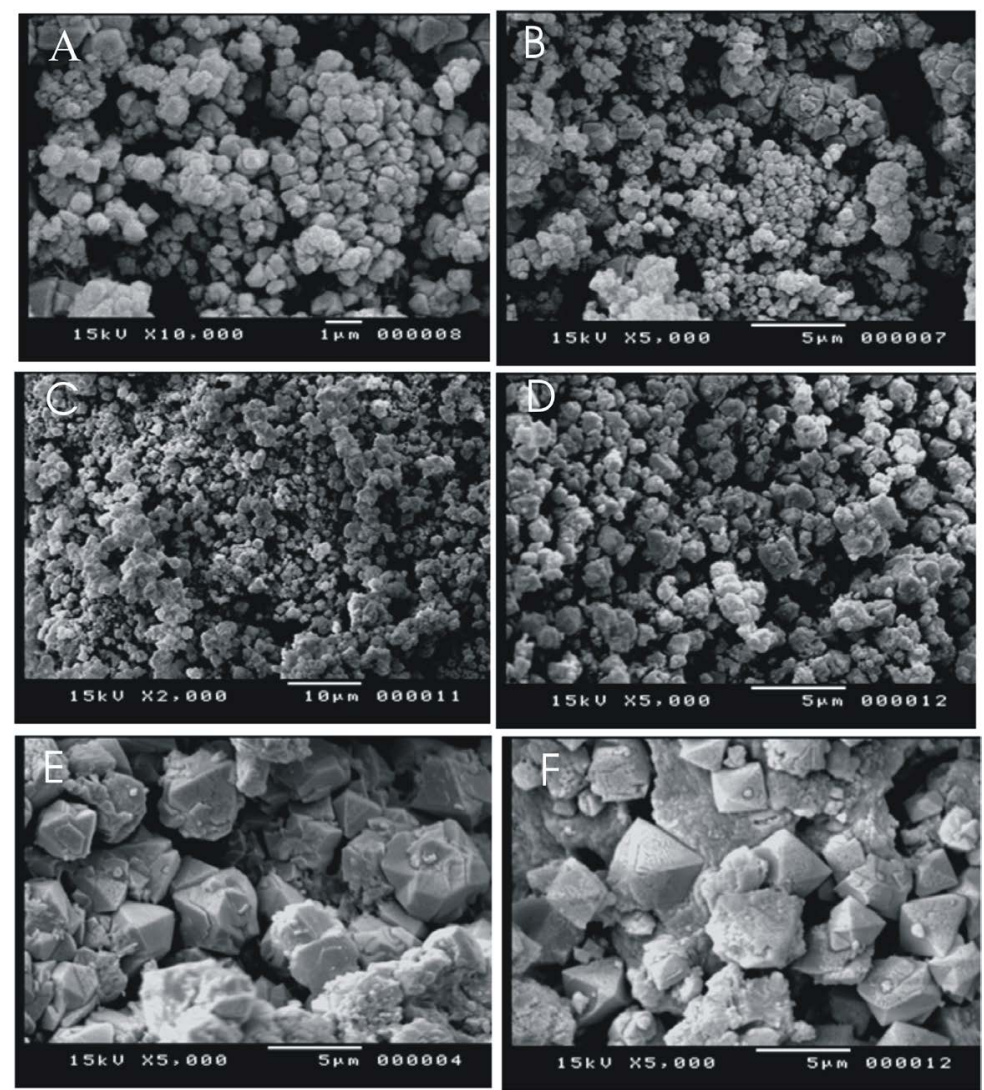

Figure 3. SEM micrographs of the prepared zeolite: A and B from kaolinite raw material; C and D from smectite-rich clay; E and F from kaolinite-smectite clay.

Table 1. Important IR-bands for Y, LTA, X type zeolites, and the synthesized zeolites from the present study.

\begin{tabular}{ccccc}
\hline & $\begin{array}{c}\text { Zeolite Y } \\
\text { (Gonghu Li, 2005) }\end{array}$ & $\begin{array}{c}\text { LTA zeolite } \\
\text { (Rios et al., 2009) }\end{array}$ & $\begin{array}{c}\text { Zeolite X } \\
\text { (Ozdemir and Piskin, 2013) }\end{array}$ & $\begin{array}{c}\text { IR-spectra for synthesized } \\
\text { zeolite }\end{array}$ \\
\hline Asymmetric stretching & $1135-725$ & $950-1250$ & $1060-971$ & $958-1000$ \\
Symmetric stretching & $1020-792$ & $660-770$ & $746-668$ & $670-672$ \\
$\begin{array}{c}\text { Double rings } \\
\text { (D4R and D6R) }\end{array}$ & 566 & $500-650$ & 560 & 564 \\
$\begin{array}{c}\text { Internal tetrahedral TO } \\
(\mathrm{T}=\mathrm{Si}, \mathrm{Al})\end{array}$ & $450-500$ & $420-500$ & 458 & $444-467$ \\
\hline
\end{tabular}

the internal linkage due to the different length of the Al-O (1.73 A) and Si-O (1.62 A) bands [25] [26]. The bands at 564, 672, 670 and 653,973,1000 are close to the bands at 560, 668 and $971 \mathrm{~cm}$, which correspond to the 6-membered double-ring vibration, to the symmetric and the asymmetric stretching respectively, zeolite $\mathrm{X}$ (Table 1). The bands at 1647 and $1648 \mathrm{~cm}$ (Lwis sites) region is assigned to the zeolitic water in the channels of zeolite [27]. The bands at spectra 3446, 3460 and 3482 are attributed to the asymmetric stretching mode of molecular water coordinated to the edges of the zeolite channels [28] [29].

\subsubsection{Thermogravimetric Analysis (DTA/TGA)}

Thermogravimetric analyses results of the synthesized zeolites are given in Figure 5. It can be seen from the thermal curves that the materials lost more than $20 \%$ of its mass under heating to $300^{\circ} \mathrm{C}$, which is considered enough to deduce that it can absorb significant amounts of water [19]. At temperature between $300^{\circ} \mathrm{C}$ and $1000^{\circ} \mathrm{C}$, mass losses ranged from $1 \%$ to $3 \%$, which means that the zeolite obtained was structurally stable. Such 

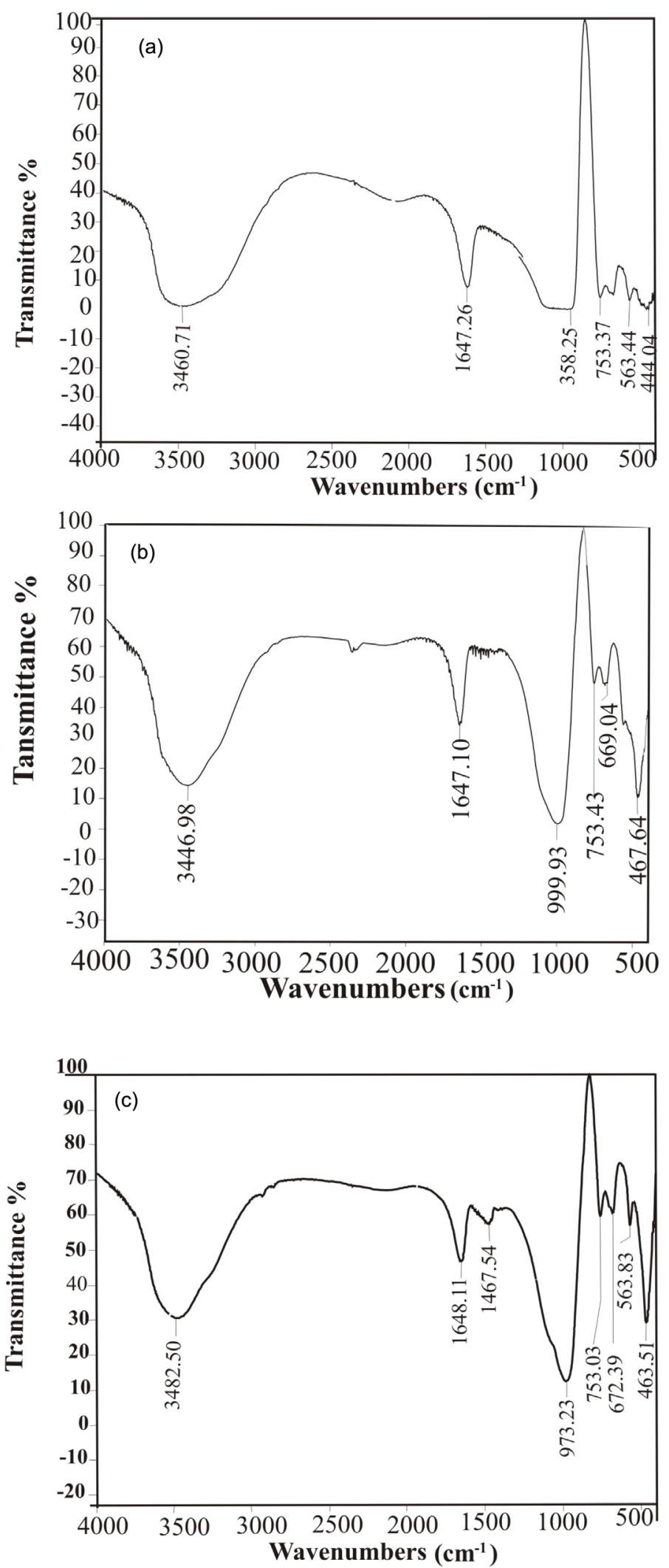

Figure 4. FTIR-Spectra for the prepared zeolites: (a) from kaolinite; (b) from smectite-rich clay; and (c) from kaolinitesmectite clay. 


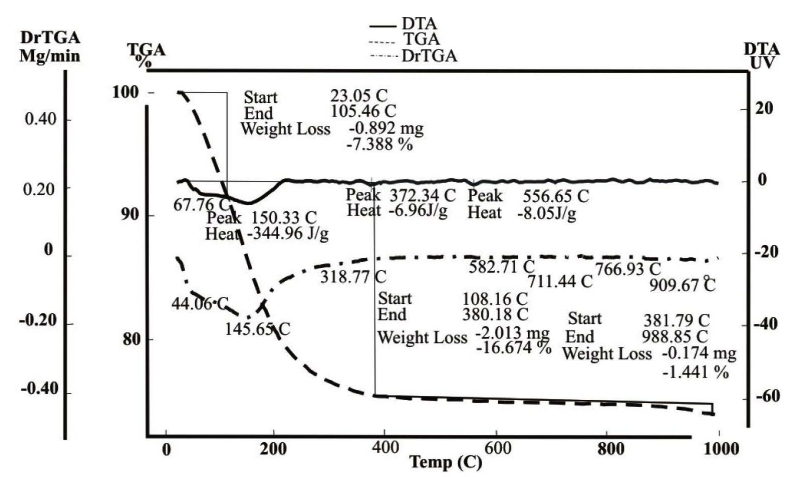

(a)

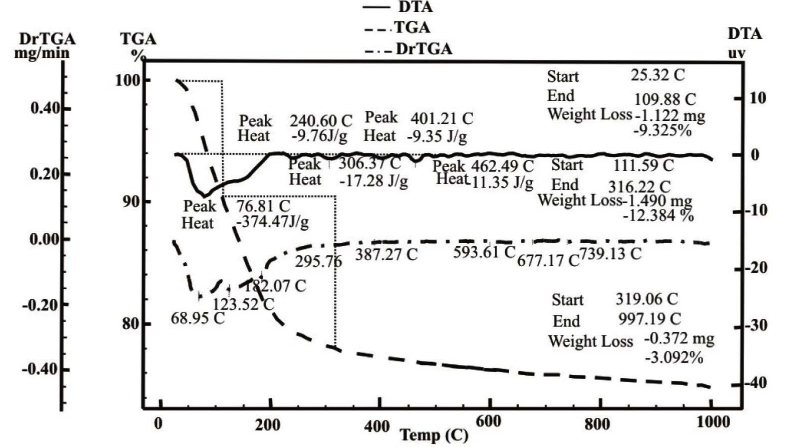

(b)

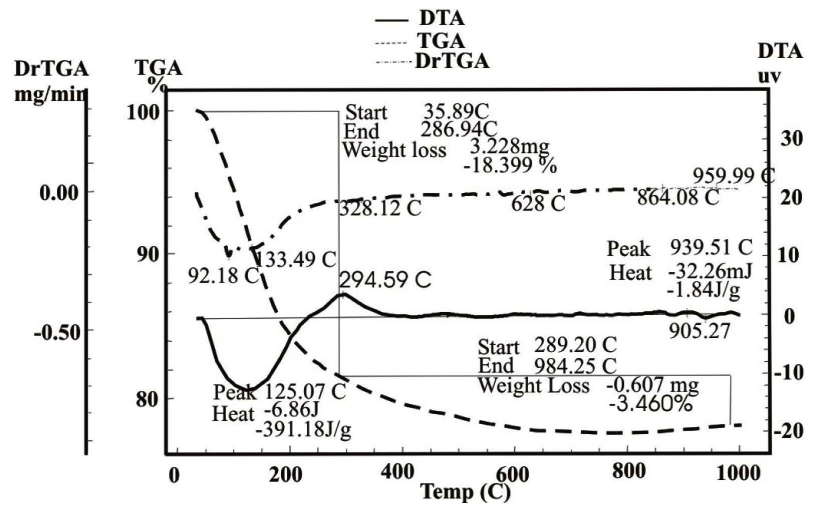

(c)

Figure 5. DTA/TGA curves of the synthetic zeolites: (a) from kaolinite; (b) from smectite-rich clay and (c) from kaolinitesmectite clay.

property is important for the synthesized zeolite which is used as a sorbent and for catalysis. The synthesized zeolites were found to be structurally stable up to $1000^{\circ} \mathrm{C}$.

\section{Heavy Metals Removal}

The increasing demands for a healthy environment, particularly with regards to high quality drinking water and removal of pollutants from industrial, agricultural and municipal wastewater, are major reason to search for new materials [4]. Zeolites have been widely used in many applications due their special properties. Adsorption is one of the special properties of zeolites. According to [30], the amount of metal ion to be adsorbed is strongly affected by nature and concentration of metal ion, $\mathrm{pH}$, and metal solubility, presence of competing and complexing ions. Many authors used the adsorption characteristic of Faujastic zeolites (X, Y and LTA) for heavy metal removal such as $\mathrm{Cu}^{+2}, \mathrm{~Pb}^{+2}, \mathrm{Cd}^{+2}$, and $\mathrm{PO}_{4}^{-3}$ [31] [32] and $\mathrm{Cr}^{+3}, \mathrm{Ni}^{+2}$ [6] [33]. In the present study, synthetic solution with 100 ppm concentrations of $\mathrm{Cr}$, Co, Ni and Mn was prepared by dilution of Merck chemical 
standard solutions (1000 ppm) for the mentioned elements.

The treatment process was begun by adding $0.5 \mathrm{gm}$ from synthetic faujasite to $100 \mathrm{ml}$ solution, and left for 1 hour on magnetic mixer using magnetic mixer at room temperature. The absorption of the metal ions $\mathrm{Cr}^{3+}, \mathrm{Co}^{2+}$, $\mathrm{Ni}^{2+}$ and $\mathrm{Mn}^{2+}$ were measured before and after treatment using atomic absorption spectrometry. The metal uptake present as a function of metal ions were $\mathrm{Cr}^{3+} 100 \%, \mathrm{Co}^{2+} 90 \%, \mathrm{Ni}^{2+} 80$ and $\mathrm{Mn}^{2+} 75 \%\left(\mathrm{Cr}^{3+}>\mathrm{Co}^{2+}>\mathrm{Ni}^{2+}>\right.$ $\left.\mathrm{Mn}^{2+}\right)$.

\section{Conclusions}

Zeolite was synthesized from Egyptian clays with different mineral compositions as raw material. Using hydrothermal reactions after fusion with $\mathrm{NaOH}$ method, the optimum conditions for hydrothermal crystallization of zeolite were found from $72 \mathrm{~h}$ to $96 \mathrm{~h}$, at $100^{\circ} \mathrm{C}$, for kaolin and smectite-rich samples, and $48 \mathrm{~h}$ for smectite-kaoline sample.

The structure of synthetic product was studied by methods of X-ray diffraction (XRD), scanning electron microscope (SEM), Fourier transform infrared spectroscopy (FT-IR) and thermogravimetric (DTA/TGA) analysis. The synthetic product was proved to have the same structure as zeolite NaX-faujasite. Thermal gravimetric analysis indicates that the synthetic material lost more than $20 \%$ of its mass under heating to $300^{\circ} \mathrm{C}$, which is considered enough to deduce that it can absorb significant amounts of water.

The experimental results regarding adsorption characteristic of synthetic faujasite for metal ions $\mathrm{Cr}^{3+}, \mathrm{Co}^{2+}$, $\mathrm{Ni}^{2+}$ and $\mathrm{Mn}^{2+}$ removal from aqueous solution showed that the synthetic faujasite exhibits a great potential for adsorption of such metal ions from water.

\section{References}

[1] Auerbach, S.M., Carrado, K.A. and Dutta, P.K. (2003) Zeolites: A Primer. Handbook of Zeolite Science and Technology, CRC Press, Boca Raton, 1. http://dx.doi.org/10.1201/9780203911167

Baccouche, A., Srasra, E. and Maaoui, M.E. (1998) Preparation of Na-P1 and Sodalite Octahydrate Zeolites from Interstratified Illite-Smectite. Applied Clay Sciences, 13, 255-273. http://dx.doi.org/10.1016/S0169-1317(98)00028-3

[2] Breck, D.W. (1974) Zeolite Molecular Sives: Structure, Chemistry and Use. John Wiley, New York.

[3] Barrer, R.M. and White, E.A. (1952) The Hydrothermal Chemistry of Silicates. Part II. Synthetic Crystalline AluminoSilicates. Journal of Chemical Society, 2, 156l-1571.

[4] Bogdanov, B., Georgiev, D., Angelova, K. and Hristov, Y. (2009) Synthetic Zeolites and Their Industrial and Environmental Applications (Review). International Science Conference, Stara Zagora, 4-5 June 2009, 5 p.

[5] Baerlocher, Ch., Meier, W.M. and Oison, D.H. (2001) Atlas of Zeoliie Framework Types. Elsevier, Amsterdam.

[6] Ríos, C.A., Williams, C.D. and Fullen, M.A. (2009) Nucleation and Growth History of Zeolite LTA Synthesized from Kaolinite by Two Different Methods. Applied Clay Science, 42, 446-454. http://dx.doi.org/10.1016/j.clay.2008.05.006

[7] Ríos, C.A., Williams, C.D. and Roberts, C. (2011) Synthesis and Characterization of SOD-CAN- and JBW-Type Structure by Hydrothermal Reaction of Kaolinite at 200 C. Dyna, No. 166, 38-47.

[8] Mezni, M., Hamzaoui, A., Hamdi, N. and Srasra, E. (2011) Synthesis of Zeolites from Low-Grade Tunisian Natural Illite by Two Different Methods. Applied Clay Science, 52, 209-218. http://dx.doi.org/10.1016/j.clay.2011.02.017

[9] Song, S. and Guo, J. (1997) Synthesis of Zeolite Y from Bentonite. Zeolites, 18, 84. http://dx.doi.org/10.1016/S0144-2449(97)84987-1

[10] Ruiz, R., Blanco, C., Gonzalez, F., Benito, I. and Lopez, J.L. (1997) Zeolitization of Bentonite and Its Application to the Removal of Ammonium Ion from Waste Water. Applied Clay Science, 12, 73-83. http://dx.doi.org/10.1016/S0169-1317(96)00038-5

[11] Cañizares, P., Duran, A., Dorado, F. and Carmona, M. (2000) The Role of Sodium Montmorillonite on Bounded Zeolite-Type Catalysts. Applied Clay Science, 16, 273-287. http://dx.doi.org/10.1016/S0169-1317(99)00058-7

[12] Boukadir, D., Bettahar, N. and Derriche, Z. (2002) Synthesis of Zeolites 4A and HS from Natural Materials. Annales de Chimie Science des Matériaux, 27, 1-13. http://dx.doi.org/10.1016/S0151-9107(02)80014-9

[13] Baccouche, A., Srasra, E. and El Maaoui, M. (1998) Preparation of Na-P1 and Sodalite Octahydrate Zeolites from Interstratified Illite-Smectite. Applied Clay Science, 13, 255-273. http://dx.doi.org/10.1016/S0169-1317(98)00028-3

[14] Selim, M.M. and Abdel-Maksoud, I.H. (2005) Preparation of Na-A Zeolite from Egyptian Kaolin. Patent No. $23,353$.

[15] Selim, M.M. and Abdel-Maksoud, I.H. (2006) Preparation of Faujasite from Egyptian Kaolin. Patent No. $23,590$.

[16] Milton, R.M. (1959) Molecular Sieve Adsorbents. US Patent 2882244. 
[17] Breck, D.W. (1964) Crystalline Molecular Sieves. Journal of Chemical Education, 41, 678-689. http://dx.doi.org/10.1021/ed041p678

[18] Htun, M.M.H., Htay, M.M. and Lwin, M.Z. (2012) Preparation of Zeolite (NaX, Faujasite) from Pure Silica and Alumina Sources. International Conference on Chemical Processes and Environmental Issues (ICCEEI), Singapore, 15-16 July 2012, 212-216.

[19] Georgiev, D., Bogdanov, B., Markovska, I. and Hristov, Y. (2013) A Study on the Synthesis and Structure of Zeolite NaX. Journal of Chemical Technology and Metallurgy, 48, 168-173.

[20] Porcher, F., Dusausoy, Y., Souhassou, M. and Lecomte, C. (2000) Epitaxial Growth of Zeolite X on Zeolite A and Twinning in Zeolite A: Structural and Topological Analysis. Mineralogical Magazine, 64, 1-8. http://dx.doi.org/10.1180/002646100549012

[21] Traa, Y. and Thompson, R.W. (2002) Controlled Co-Crystallization of Zeolites A and X. Journal of Materials Chemistry, 12, 496-499. http://dx.doi.org/10.1039/b108634k

[22] Zhao, H., Deng, Y., Harsh, J.B., Flury, M. and Boyle, J.S. (2004) Alteration of Kaolinite to Cancrinite and Sodalite by Simulated Handford Tank Waste and Its Impact on Cesium Retention. Clays and Clay Minerals, 52, 1-13. http://dx.doi.org/10.1346/CCMN.2004.0520101

[23] Lapides, I. and Heller-Kallai, L. (2007) Reactions of Metakaolinite with NaOH and Colloidal Silica-Comparison of Different Samples (Part 2). Applied Clay Science, 35, 94-98. http://dx.doi.org/10.1016/j.clay.2006.06.007

[24] Jentys, A. and Lercher, J.A. (2001) Surface Modification of HZSM-5 Zeolites. In: van Bekkum, H., Flanigen, E.M., Jacobs, P.A. and Jensen, J.C., Eds., Studies in Surface Science and Catalysis (Vol. 137), Elsevier Science B.V., Amsterdam, 345.

[25] Li, G.H. (2005) FT-IR Studies of Zeolite Materials: Characterization and Environmental Applications. Ph.D. Thesis, Graduate College, The University of Iowa, Iowa City, 162.

[26] Mohammed, A.A., Shakir, I.K. and Esgair, K.K. (2013) The Use of Prepared Zeolite Y from Iraqi Kaolin for Fluid Catalytic Cracking of Vacuum Gas Oil. Journal of Engineering, 19, 1256-1270.

[27] Blanco, C., Gonzalez, F., Pesquera, C., Benito, I., Mendioroz, S. and Pajares, J.A. (1989) Differences between One Aluminic Palygorskite and Another Magnesic by Infrared Spectroscopy. Spectroscopy Letters, 22, 659-673. http://dx.doi.org/10.1080/00387018908053926

[28] Zhao, D., Zhou, J. and Liu, N. (2006) Preparation and Characterization of Mingguang Palygorskite Supported with Silver and Copper for Antibacterial Behavior. Applied Clay Science, 33, 161-170. http://dx.doi.org/10.1016/j.clay.2006.04.003

[29] Faghihian, H. and Godazandeha, N. (2009) Synthesis of Nano Crystalline Zeolite Y from Bentonite. Journal of Porous Materials, 16, 331-335. http://dx.doi.org/10.1007/s10934-008-9204-0

[30] Ikhsan, J., Johnson, I.B.B. and Wells, J.D. (1999) A Comparative Study of the Adsorption of Transition Metals on Kaolinite. Journal of Colloid and Interface Science, 217, 403-410. http://dx.doi.org/10.1006/jcis.1999.6377

[31] Kugbe, J., Matsue, N. and Henmi, T. (2009) Synthesis of Linde Type A Zeolite-Goethite Nanocomposite as an Adsorbent for Cationic and Anionic Pollutants. Journal of Hazardous Materials, 164, 929-935. http://dx.doi.org/10.1016/j.jhazmat.2008.08.080

[32] Ibrahim, H.S., Jamil, T.S. and Hegazy, E.Z. (2010) Application of Zeolite Prepared from Egyptian Kaolin for the Removal of Heavy Metals: II. Isotherm Models. Journal of Hazardous Materials, 182, 842-847. http://dx.doi.org/10.1016/j.jhazmat.2010.06.118

[33] Hani, H.A., El-Sayed, M.M.H., Mostafa, A.A., El-Defrawy, N.M. and Sorour, M.H. (2012) Removal of Cr(III) in Batch and Pilot Scale Dynamic System Using Zeolite NaA Prepared from Egyptian Kaolin. International Journal of Chemical and Environmental Engineering, 3, 158-166. 